\title{
Gender features in pronoun resolution processing in Brazilian Portuguese
}

\author{
Michele Alves*
}

\begin{abstract}
Given the fact that the parser has a very restrictive focus of attention, it is memory retrieval that helps us to bind antecedents and pronouns in coreference, which is considered a long distance dependency. Our memory seems to work in a content-addressable way (McElree, 2000; McElree et al, 2003; van Dyke and McElree, 2006), that is, all the antecedent candidates that match the pronoun cues are simultaneously accessed and the correct antecedent is retrieved. However, memory can suffer interference from distractors (Lewis \& Vasishth, 2005; Lewis, Vasishth \& van Dyke, 2006), items that are similar to the antecedent. Consequently the strength of association between the pronoun's cues and the antecedent's features reduces, and distractors can be retrieved instead of the antecedent. According to some psycholinguistic studies, at least two kinds of cues might play a role in this process: the structural constraints related to Principle B and agreement between antecedents and pronouns. This research aims to investigate how nominal antecedents are retrieved in Brazilian Portuguese, which is a language with morphology richness. The question is whether the structural constraints cues and the agreement cues would have the same influence in coreference processing. Moreover, a comparison between different types of agreement features will also be examined in order to find out whether memory retrieves feminine features differently from masculine; and whether grammatical gender, which is an invariable and arbitrary gender, is retrieved differently from semantic gender, which is related to the biological gender of the referent. The results of an eye-tracking study conducted with 24 native speakers of Brazilian Portuguese indicate that at the beginning of coreference processing, the only cues that are taken into account are the gender features. Interestingly, feminine and grammatical gender features were responsible for greater influences in both grammatical and ungrammatical sentences. On the other hand, the structural constraints seem to play a major role at later processing phases. Additionally, an offline grammatical judgment experiment with the same materials used in the previous experiment was conducted with forty native speakers of Brazilian Portuguese. The results confirmed the eye-tracking findings as it seems that the presence of attractors influenced on-line and off-line processing as well as the comprehension of the sentences. Therefore, ungrammatical sentences with attractors were treated as grammatical and grammatical sentences with attractors were treated as ungrammatical. Besides that, ungrammatical sentences were also vulnerable to semantic illusions in the presence of attractors, that is, distractors were retrieved as semantic referents.
\end{abstract}

Keywords. coreference processing; gender features; Brazilian Portuguese

\footnotetext{
* I would like to thank the participants that contributed in the experiments reported in this paper as well as the funding provided by CNPq, CAPES, and Fulbright. Authors: Michele Alves, Federal University of Rio de Janeiro (michelecalil@gmail.com).
} 
1. Introduction. In language comprehension, we not only process the linguistic input, but we store the already processed information in memory in order to be integrated with upcoming material so that the grammatical dependencies can be created. It is the cue-based memory retrieval mechanism that mediates the creation of the grammatical dependencies so that parsing success depends on the extent that required constituents can be retrieved from memory (McElree, 2000; McElree et al, 2003; van Dyke and McElree, 2006). Thus if memory is so important for language processing, one could ask what happens when memory cannot elicit a good target, that is, what would happen, for example, in a binding dependency context with multiple or no pronominal antecedents? What are the strategies that our memory and the parser have in these cases?

The present study will investigate how pronouns retrieve nominal antecedents, and, more specifically, we are interested in clarifying which factors may influence antecedent retrieval as well as their time-course in processing. In order to retrieve their antecedents, pronouns seems to rely on Principle $\mathrm{B}$, which states that the antecedents must not be located at the pronouns local domain (Chomsky, 1981). However, other factors such as agreement between pronouns and antecedents also seem to play an important role (cf. Cacciari et al, 1997; De Vicenzi \& Di Domenico, 1999; Arnold et al, 2000; Kennison, 2003, Rigalleau et al, 2004, etc). It should be noted that other factors related to discourse salience and pragmatics might also be fundamental for coreference (cf. Gordon et al, 1993; Grosz, Joshi \& Weinstein, 1995; Badecker \& Straub, 2002, etc). However, for methodological reasons, the present study will be focused on discussing only Principle B and agreement factors.

Therefore, given the fact that agreement may be crucial for antecedent retrieval, a language with morphological richness such as Brazilian Portuguese can be seen as an interesting window to investigate the influence of agreement in coreference processing. Our hypothesis is that because of its rich morphology, Brazilian Portuguese would have more influence of agreement features than structural constraints. In addition, we hypothesize that memory is not as abstract as one may think, in the sense that not all cues may be accessed at the same way. In other words, taking into account that there are different ways in which linguistic information may be encoded, it is possible that its storage may also be done differently depending on the type of feature, resulting in differences in memory access, and consequently, in processing. With this in mind, we chose to study the influence of gender agreement in coreference processing due to its variety of features. Besides the difference between masculine and feminine, which is very common among the languages, one can also find differences between grammatical and semantic genders. As grammatical gender is intrinsic, arbitrary and invariable in the language, it is probably specified in the lexicon given its idiosyncratic nature (Chomsky, 1995); while semantic gender has strong connections to the biological gender of the referents. The nouns that have grammatical gender are called epicenes. Interestingly there is evidence that coreference is faster when the antecedents have grammatical gender than when the antecedents have semantic gender (Cacciari et al, 1997; Cacciari et al, 2011). And since Brazilian Portuguese has both grammatical and semantic genders, our research might be able to drawn fruitful conclusions about the influence of these types of features in memory retrieval.

\section{Memory and the relationship between structural constraints and agreement features}

Because we have a very restrictive focus of attention, it is memory that makes language processing possible. And there is strong evidence in both psycholinguistic and computational 
literature in favor of Content-Addressable Memory (CAM), which states that memory activation is based on parallel content association, and not serial search (McElree, 2000; McElree et al, 2003; van Dyke and McElree, 2006). However, memory can suffer interference caused by similarity effects of the distractors, which can precede or follow the target. When this happens, the strength of association between the cues and the target reduces and latencies of failing rates increase. Consequently, our memory can retrieve the distractors instead of the targets (Lewis \& Vasishth, 2005; Lewis, Vasishth \& van Dyke, 2006).

Adapting for coreference, pronouns would generate a set of cues that would simultaneously activate all the items that content-match them, so that the target, which, in this case, is the antecedent, would be retrieved. According to the structural constraint cues, the target is the candidate that respects Principle B, that is, it cannot be within the pronoun domain. On the order hand, the agreement cues do not take Principle B into account, and for them the correct antecedent should simply feature-match the pronoun cues. This way, on one hand, the target would be the structurally acceptable candidate that feature-match the pronoun cues; and, on the other hand, the distractor would be a partial-match similar to the target, a candidate that also feature-matches the pronoun, but it is structurally unacceptable, since it is located within the pronoun domain. In this paper, distractors would be called attractors.

The complex relationship between structural constraints and agreement features is object of great debate in literature. It was found that not all cues have the same weight in the cue-based retrieval mechanism (cf. van Dyke \& McElree, 2011 for syntactic and semantic cues). It seems that in certain grammatical dependencies such as anaphora the only cue that is taken into account is the structural constraints of Principle A, and agreement cues seem to have no influence in memory retrieval (Xiang et al, 2009; Phillips et al, 2011; Dillon et al, 2013 for anaphoras; Chow et al, 2014 for pronouns). Therefore, while some studies defend that the structural constraints are so strong that they prevent any kind influence from structurally unacceptable candidates, others show numerous discrepancies regarding the time-course of the influence of the structural constraints and the agreement features.

Some studies defend binding as initial filter (Nicol \& Swinney, 1989; Clifton et al, 1997), that is, initially only candidates that are licensed by Principle B can be considered as antecedents; and only in cases where there is not a good match between the pronouns and the antecedents, other candidates can be taken into account. On the other hand, other studies provide evidence for a constraint-based account (Badecker \& Straub, 2002), in which all the discourse salient candidates that feature-match the pronoun in gender and in number are considered potential antecedents at early processing phases, and then the structural constraints would operate quickly in order to help the parser to select the correct antecedent. A third possibility is the defeasible filter account (Sturt, 2003), which was initially used to describe anaphoras. According to this view, the initial candidate set is only composed by those antecedent candidates that respect binding constraints; however, at a later point in processing, other candidates that were initially ruled out could be accessed by the parser when there is not a good match between the structurally acceptable antecedent and the pronoun. More recently, Cunnings and Ferser (2013) found a late effect of structurally unacceptable antecedents in anaphora processing, and when they appeared closer to the reflexive, an early effect of these candidates was found. Patil et al (2016) also showed an early influence of structurally unacceptable antecedents in anaphor processing, arguing that gender may play an important role as one of the retrieval cues that is 
used by the parser. Moreover, it is relevant to say that the influence of structural cues was only detected at late processing phases.

The fact is that reference processing is still a mystery for psycholinguistics; therefore, this research will fill a gap in literature as it will investigate not only how coreference processing takes place in a language with rich morphology such as Brazilian Portuguese, but also it will compare different types of gender agreement cues (masculine versus feminine and grammatical versus semantic gender). If our hypothesis proves true, we will find strong effects of agreement cues throughout coreference processing given the fact that speakers of Brazilian Portuguese may be used to lean on morphological information. Therefore, a novel approach different from the ones mentioned in the previous paragraph should be considered. Moreover, we hypothesize that memory is not that abstract so that we expect to find differences depending on the type of the gender features displayed by the attractors. Unlike masculine, feminine gender is generally represented by an overt morpheme in Brazilian Portuguese, and for this reason it is considered to be marked and salient. Taken this into account, we will probably find more influence of feminine than masculine attractors in coreference processing. Greater influence effects of attractors with grammatical gender are also expected as it may be quickly accessed by the parser due to the fact that this type of gender is probably specified in the lexicon.

\section{Eye-tracking experiment}

3.1 PARTICIPANTS. Twenty-nine native speakers of Brazilian Portuguese volunteers residing in Rio de Janeiro, Brazil participated in the experiment. They all have normal or corrected-tonormal vision and were undergraduate students of the Federal University of Rio de Janeiro (UFRJ) and were randomly invited to participate in this study. All participants were naive in relation to the real object of the study of the experiment; however, they were aware of the general purpose of the research as well as its task, and gave written permission to have the results published by signing a consent form, which also stated that the task they would perform would not bring any risks to their health. They received three hours of Cultural-Scientific Activities (Atividades-Científico-Culturais Discentes, AACC), which is mandatory for their graduation, as compensation for their work. It is relevant to mention that five participants were excluded from analysis as they had less than $80 \%$ of their eyes movements recorded. Consequently, the experiment was analyzed using data from twenty-four participants, more specifically twenty female and four male with a mean age of 22.2 years.

3.2 DESIGN AND MATERIALS. The independent variables of the experiment were: grammaticality of the sentence, which is directly related to Principle B structural constraints, (grammatical or ungrammatical), the presence of attractor (presence or absence), and the type of attractor (masculine, feminine, feminine epicene, or masculine epicene). Therefore, our experimental design was $2 \times 2 \times 4$ with sixteen conditions.

Each of the four lists, which were elaborated using a Latin Square, was pseudo-randomized and composed by twenty-four experimental sentences and thirty-two fillers. Of the twenty-four sentences, six contained a masculine attractor, six a feminine attractor, six a masculine epicene and six a feminine epicene. Both experimental and filler sentences were accompanied by final comprehension questions. Filler questions were balanced between yes and no answers.

Our experiment was composed by two on-line and one off-line dependent variables. The on-line dependent variables were the First and Total Fixation Durations at the pronoun areas. The First Fixation Duration measures how long it takes to read the pronouns when they are first 
encountered, whereas the Total Fixation Duration corresponds to the sum of all the eye fixations at the pronoun areas. Finally, the off-line dependent variable corresponds to the answers to the comprehension questions, which purpose was to check whether the readers were semantically retrieving the structurally acceptable antecedent candidate or not.

One can find a sample of the materials used in the experiment below ${ }^{2}$ :

\section{a. Ungrammatical sentence with feminine attractor}

O botânico sempre que pode visita a bióloga que levou ela para a área.

"The botanist [masc] always visit when it's possible the biologist [fem] that took her to the field."

b. Ungrammatical sentence without feminine attractor

O botânico sempre que pode visita o biólogo que levou ela para a área.

"The botanist [masc] always visit when it's possible the biologist [masc] that took her to the field."

c. Grammatical sentence with feminine attractor

A botânica sempre que pode visita uma bióloga que levou ela para a área.

"The botanist [fem] always visit when it's possible the biologist [fem] that took

her to the field."

d. Grammatical sentence without feminine attractor

A botânica sempre que pode visita o biólogo que levou ela para a área.

"The botanist [fem] always visit when it's possible the biologist [masc] that took her to the field."

\section{e. Comprehension question}

A botânica foi levada para o campo?

"Was the botanist taken to the field?"

3.3 PROCEDURE. The experiment was conducted at the laboratory of experimental research (LAPEX) at the Federal University of Rio de Janeiro (UFRJ) in Rio de Janeiro, Brazil. The eyetracker used in this experiment was Tobii Studio ${ }^{T M} T X$ 300, which requires an initial individual calibration in the beginning of the procedure for the eye-tracker to be able to monitor the participant's pupils during the reading task. The participants were instructed to seat comfortable and were given written and oral task instructions. After that, calibration process would start followed by a short practice with filler sentences so that the experimenter would check whether the participants understood the task and were performing it at a natural speed. Ultimately, the experimenter would leave the participants alone in a quiet room without any distractions. Each participant performed randomly one of the four lists of the experiment. The experiment duration was of twenty minutes approximately.

3.4 RESUlTS. Data was extracted using Tobii Fixation Filter, which is the default fixation algorithm in Tobii Studio ${ }^{T M} 2 . X$ version 2.2. It should be noted that our data did not have any outliers trimming or transformation and was analyzed at $\mathrm{R}^{3}$ statistics software, using plotrix ${ }^{4}$, lmer Test ${ }^{5}$, and ggplot $2^{6}$ packages.

\footnotetext{
${ }^{2}$ It is relevant to mention that the conditions called without attractor are those in which the noun that occupies the attractor position does not gender-match the pronoun.

${ }^{3}$ R Core Team (2016). R: A language and environment for statistical computing. R Foundation for Statistical Computing, Vienna, Austria (https://www.r-project.org/)
} 
Means as well as standard errors of First Fixation Duration at the pronoun area were reported for each condition in Table 1:

\begin{tabular}{|c|c|c|c|c|}
\hline & $\begin{array}{c}\text { Masculine } \\
\text { attractor }\end{array}$ & $\begin{array}{c}\text { Feminine } \\
\text { attractor }\end{array}$ & $\begin{array}{c}\text { Masculine } \\
\text { Epicene }\end{array}$ & $\begin{array}{c}\text { Feminine } \\
\text { Epicene }\end{array}$ \\
\hline $\begin{array}{c}\text { Ungrammatical sentence } \\
\text { with attractor }\end{array}$ & $277(27)$ & $289(31)$ & $274(26)$ & $231(23)$ \\
\hline $\begin{array}{c}\text { Ungrammatical sentence } \\
\text { without attractor }\end{array}$ & $315(30)$ & $292(19)$ & $274(27)$ & $357(66)$ \\
\hline $\begin{array}{c}\text { Grammatical sentence with } \\
\text { attractor }\end{array}$ & $270(20)$ & $312(34)$ & $342(34)$ & $286(50)$ \\
\hline $\begin{array}{c}\text { Grammatical sentence } \\
\text { without attractor }\end{array}$ & $317(22)$ & $245(16)$ & $333(46)$ & $354(57)$ \\
\hline
\end{tabular}

Table 1: First Fixation Duration means and standard errors in milliseconds for each experimental condition

A linear mixed-effect model was created with the help of lmerTest package. Its fixed effects were: grammaticality of the sentence, presence of attractor, and type of attractor, while its random effects were: participants and items. And by using the anova function, we found a significant effect of the interaction between presence of attractor and type of attractor in our First Fixation Duration model: $\mathrm{F}(4,0.015)=2.62, \mathrm{p}=0.03$.

To figure out which pair of conditions were significantly different, bar plots with $95 \%$ confidence intervals were created with the help of ggplot 2 package. Figures 1, 2, and 3 show how attractors with feminine gender interfere in coreference processing in ungrammatical and grammatical sentences.

\section{First Fixation Duration in ungrammatical sentences}

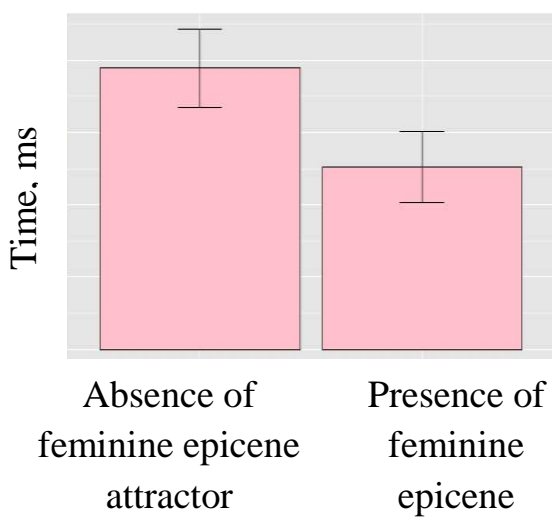

Figure 1. Barplot with 95\% confidence intervals showing First Fixation Duration in grammatical sentences with and without feminine epicene attractors

\footnotetext{
${ }^{4}$ Lemon, J. (2006) Plotrix: a package in the red light district of R. R-News, 6(4): 8-12.

${ }^{5}$ Alexandra Kuznetsova, Per Bruun Brockhoff and Rune Haubo Bojesen Christensen (2015). 1merTest: Tests in Linear Mixed Effects Models. R package version 2.0-29 (https://CRAN.R-project.org/package=lmerTest)

${ }^{6}$ H. Wickham. ggplot2: Elegant Graphics for Data Analysis. Springer-Verlag. New York, 2009.
} 
It can be observed in Figure 1 that in ungrammatical sentences, coreference processing is faster in sentences with feminine epicene attractors than in sentences without (T-test, $\mathrm{p}=0.01$ ). On the other hand, Figure 2 illustrates that in the case of grammatical sentences, coreference is slower in sentences with feminine attractors than in sentences without (T-test, $\mathrm{p}=0.04)$.

\section{First Fixation Duration in grammatical sentences}

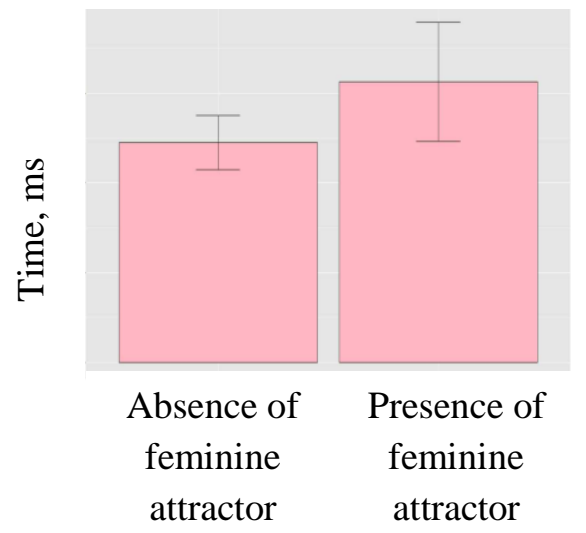

Figure 2. Barplot with 95\% confidence intervals showing First Fixation Duration in grammatical sentences with and without feminine attractors

Table 2 contains means along with standard errors of Total Fixation Duration at the pronoun area for each condition:

\begin{tabular}{|c|c|c|c|c|}
\hline & $\begin{array}{c}\text { Masculine } \\
\text { attractor }\end{array}$ & $\begin{array}{c}\text { Feminine } \\
\text { attractor }\end{array}$ & $\begin{array}{c}\text { Masculine } \\
\text { Epicene }\end{array}$ & $\begin{array}{c}\text { Feminine } \\
\text { Epicene }\end{array}$ \\
\hline $\begin{array}{c}\text { Ungrammatical sentence } \\
\text { with attractor }\end{array}$ & $667(103)$ & $732(81)$ & $409(47)$ & $756(170)$ \\
\hline $\begin{array}{c}\text { Ungrammatical sentence } \\
\text { without attractor }\end{array}$ & $688(84)$ & $583(62)$ & $598(133)$ & $487(98)$ \\
\hline $\begin{array}{c}\text { Grammatical sentence with } \\
\text { attractor }\end{array}$ & $452(63)$ & $512(63)$ & $468(71)$ & $438(76)$ \\
\hline $\begin{array}{c}\text { Grammatical sentence } \\
\text { without attractor }\end{array}$ & $534(66)$ & $666(107)$ & $500(93)$ & $553(98)$ \\
\hline
\end{tabular}

Table 2: Total Fixation Duration means and standard errors in milliseconds for each experimental condition

A linear mixed-effect model was also created with the help of lmerTest package. Its fixed and random effects were the same of the First Fixation Duration model. And by using the anova function, we found a significant main effect of grammaticality of the sentence in our Total Fixation Duration model: $\mathrm{F}(1,0.109)=7.97$, p=0.007.

Figures 3 and 4 illustrates how the factor grammaticality of the sentence affected coreference in grammatical and in ungrammatical sentences. It was found that coreference processing is faster in grammatical sentences than in ungrammatical sentences despite the presence of feminine $(\mathrm{T}$ test, 0.01) and masculine attractors (T-test, 0.04). 


\section{Total Fixation Duration in sentences with feminine attractors}

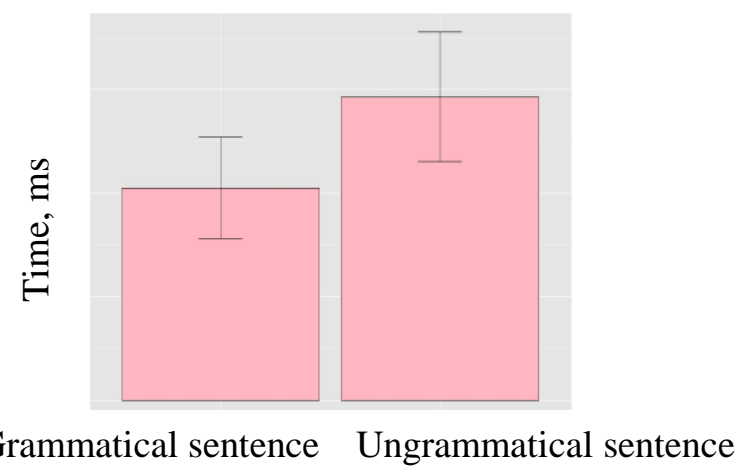

Figure 3. Barplot with 95\% confidence intervals showing Total Fixation Duration in grammatical and ungrammatical sentences with feminine attractors

\section{Total Fixation Duration in sentences with masculine attractors}

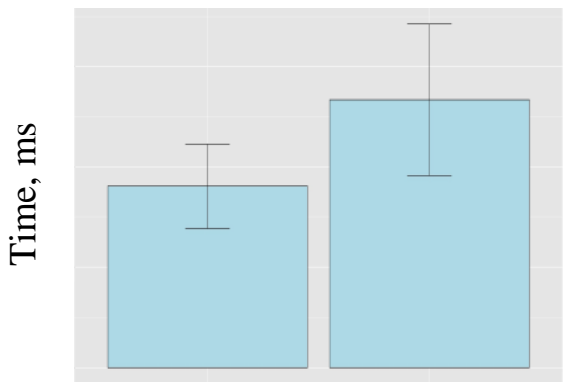

Grammatical sentence

Ungrammatical sentence

Figure 4. Barplot with 95\% confidence intervals showing Total Fixation Duration in grammatical and ungrammatical sentences with masculine attractors

The difference between masculine/feminine and masculine/feminine epicene attractors, that is, attractors with semantic gender and grammatical gender, was not pervasive in the results.

Although the there was only a moderate trend towards significance (T-test, $\mathrm{p}=0.06$ ), it seems that in grammatical sentences, feminine epicene attractors were responsible for slower First Fixation Duration in comparison to feminine attractors as shown in Figure 5.

\section{First Fixation Duration in grammatical sentences}

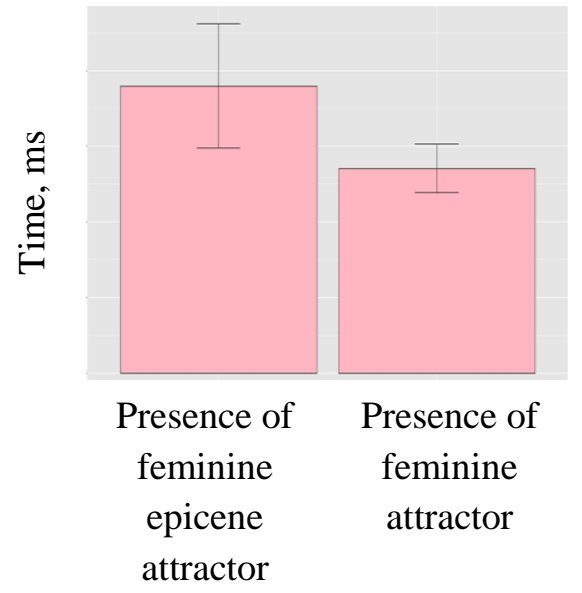


Figure 5. Barplot with 95\% confidence interval showing First Fixation Duration in grammatical sentences with feminine epicene and feminine attractors

In relation to Total Fixation Duration, one can observe in Figure 6 that in ungrammatical sentences, sentences with masculine epicenes had slower coreference when compared to sentences with masculine epicene attractors ( $\mathrm{T}$-test, $\mathrm{p}=0.01$ ).

\section{Total Fixation Duration in ungrammatical sentences}

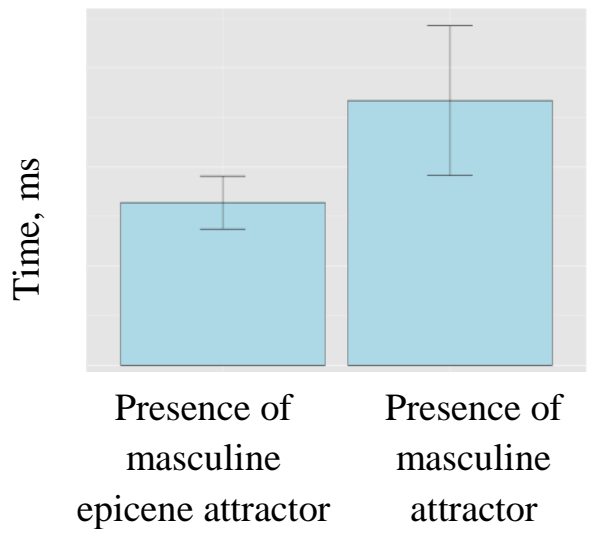

Figure 6. Barplot with 95\% confidence intervals showing Total Fixation Duration in ungrammatical sentences with masculine epicene and masculine attractors

The comprehension questions in the end of each experimental sentence were used to check whether the readers were semantically retrieving the structurally acceptable antecedent candidate. Consequently, if this is the case, their answer to the questions as in (1e) would be "yes". The off-line results of the comprehension questions (Fisher Test with simulated p-value based on $2 \mathrm{e}+05$ replicates, $\mathrm{p}<0.0001)$ can be seen in Table 3:

\begin{tabular}{|c|c|c|c|c|}
\hline & $\begin{array}{c}\text { Masculine } \\
\text { attractor }\end{array}$ & $\begin{array}{c}\text { Feminine } \\
\text { attractor }\end{array}$ & $\begin{array}{c}\text { Masculine } \\
\text { Epicene }\end{array}$ & $\begin{array}{c}\text { Feminine } \\
\text { Epicene }\end{array}$ \\
\hline $\begin{array}{c}\text { Ungrammatical sentence } \\
\text { with attractor }\end{array}$ & $41 \%$ & $38 \%$ & $67 \%$ & $40 \%$ \\
\hline $\begin{array}{c}\text { Ungrammatical sentence } \\
\text { without attractor }\end{array}$ & $43 \%$ & $61 \%$ & $33 \%$ & $50 \%$ \\
\hline $\begin{array}{c}\text { Grammatical sentence with } \\
\text { attractor }\end{array}$ & $78 \%$ & $92 \%$ & $83 \%$ & $100 \%$ \\
\hline $\begin{array}{c}\text { Grammatical sentence } \\
\text { without attractor }\end{array}$ & $79 \%$ & $78 \%$ & $100 \%$ & $100 \%$ \\
\hline
\end{tabular}

Table 3: Yes-Anwers to the comprehension questions in percentage

The answers to the comprehension questions show that the attractors that can influence the comprehension of coreference most are the feminine attractors and the masculine epicene attractors. It seems that the answers to the questions of sentences with masculine and feminine epicenes only showed effects of grammaticality.

3.5 DISCUSSION. The results of the eye-tracking experiment suggest that agreement features play an important role at the beginning of coreference processing, as all candidates that gender-match 
the pronoun are considered as potential antecedents by the parser, despite the fact they are not structurally acceptable according to the structural constraints of Principle B. On the other hand, at late processing phases, it is Principle B structural constraints that seemed to influence coreference processing. This way, our findings provide evidence in favor of the constraint-based account (Badecker \& Straub, 2002).

Another contribution of this study is that it seems that memory is not that abstract as we thought, so that not all cues have the same weight in memory. Probably because feminine features are salient and marked, they can influence memory retrieval more than masculine features. Moreover, it seems that grammatical gender displayed by epicenes has different effects in coreference processing when compared to other attractors with semantic gender. In the present study, at early processing measures, in ungrammatical sentences, there was a marginal difference between feminine epicene attractors and feminine attractors, more specifically, the former were responsible for slower coreference than the latter. It is possible that the grammatical gender of the epicene attractors is accessed faster than the semantic gender of the feminine attractors, and as in ungrammatical sentences they are the only candidates that feature-match the pronoun cues, they may be responsible for stronger interference effects.

On the other hand, at a late processing phase, in grammatical sentences, the opposite happens: masculine epicene attractors were responsible for significant faster coreference than masculine attractors. It is known that in grammatical sentences, differently from ungrammatical ones, there are multiple candidates that gender-match the pronoun cues (the structurally acceptable candidate and the attractor); therefore, the parser needs to make a decision between two potential antecedents. According to our model, it seems that at a late processing phase, the structural constraints of Principle B may play a role in helping the parser to choose the correct antecedent. From this point of view, the parser needs to discard the attractor. This way, although the grammatical gender of the epicene attractor matches the pronoun, this type of attractor can be quickly discarded by the parser not only because it violates Principle B, but more importantly, because its features are quickly accessed by memory.

The differences between ungrammatical and grammatical sentences were also found in other contexts of this study. At early processing measures, ungrammatical sentences with feminine epicene attractors displayed facilitated coreference when compared to the same sentences without attractors. This may be due to the no-antecedent effect, also found in Badecker \& Straub (2002). In ungrammatical sentences, the attractor is the only candidate that match the pronoun cues, as a result, the parser tends to consider it as a potential antecedent, especially when its features are so salient and easily accessible as the features of the feminine epicenes. However, in the case of grammatical sentences with feminine attractors, as explained before, there are multiple antecedent candidates, and because the structural constraints do not seem to operate at this point, the parser has great difficulties in retrieving the correct antecedent from memory, resulting in slower coreference processing. This effect is called multiple-match and was found in Badecker and Straub (2002) as well.

It is relevant to say that the no-antecedent and the multiple-match effects are actually evidences in favor of the Content-Addressable Memory (CAM) approach (McElree, 2000; McElree et al, 2003; van Dyke and McElree, 2006). According to Dillon et al (2013), facilitation effects of structurally unacceptable antecedents in ungrammatical sentences, also known as intrusion effects, provide evidence that the antecedent retrieval in memory leans on content-cues such as the agreement features. On the other hand, the authors explain that the processing difficulty in 
grammatical sentences with attractors is a result of the similarity-based interference effects (Lewis \& Vasishth, 2005; Lewis, Vasishth \& van Dyke 2006) caused by the fact that the structurally unacceptable candidate also feature-matches the pronoun.

In terms of coreference comprehension, in ungrammatical sentences, the semantic retrieval of the structurally acceptable antecedent was negatively affected in the presence of feminine attractors, which may be considered a strong piece of evidence to the fact that the feminine attractors are actually being retrieved by memory not only as potential antecedents, but also as semantic referents. It is possible that in these contexts, the parser may be operating under both a grammatical and a semantic illusion. On the contrary, the masculine epicene attractors are not considered good semantic referents in ungrammatical sentences, which is congruent to the fact that they are quickly discarded by the parser at late processing phases as discussed before. In this way, it seems that rather than retrieving the masculine epicene attractors, the readers prefer to retrieve the structurally acceptable antecedents as the semantic referents in spite of the fact they feature-mismatch the pronoun cues. In this case, the parser may be working under a grammatical illusion, that is, the parser may be considering ungrammatical sentences grammatical.

However, with respect to grammatical sentences, the paradigm changes, masculine epicene attractors turn out to be potential semantic referents, which might be a consequence of the fact that it is the unmarked and default gender. However, the same is not true for feminine attractors, as they are not considered good semantic referents, which may be due to the fact that the feminine is a marked gender in the language.

In order to better understand the grammatical illusions encountered in the off-line measures of the eye-tracking experiment, we conducted an off-line grammaticality judgment. Our main aim was to check whether ungrammatical sentences with attractors, especially feminine ones, could be treated as grammatical in comprehension. In addition, we will investigate whether grammatical sentences with attractors would resemble ungrammatical sentences, which would be considered an illusion of ungrammaticality. Finally, we will be interested in figuring out which types of attractors are responsible for greater or less interference.

\section{The off-line acceptability judgment experiment}

4.1 PARTICIPANTS. Forty native speakers of Brazilian Portuguese, undergraduate students of the Federal University of Rio de Janeiro (UFRJ) participated in the experiment. They were all volunteers and received one hour of Cultural-Scientific Activities (Atividades-CientíficoCulturais Discentes, AACC) as compensation for their work. It is relevant to say none of these participants were the same of the eye-tracking experiment and that they were all naive in relation to our object of the study.

4.2 DESIGN AND MATERIALS. We conducted a Likert Scale task with the same sentences that were used in the eye-tracking experiment, thus the independent variables and the design were also the same. The dependent variable in this experiment is the rate that the participants gave to each sentence, which varied from one to five, 1 for very unnatural, 2 for natural, 3 for OK, 4 for natural and 5 for very natural.

4.3 PROCEDURE. The experiment was conducted in quiet classrooms at the Letters Faculty in the Federal University of Rio de Janeiro (UFRJ). The experimenter gave the participants oral instructions before handing them the handouts, which contained the materials with written instructions and proper spaces above each sentence for the participants to mark their answers. 
4.4 RESULTS. Z-scores were calculated for each piece of data in order to minimize the subject variability in relation to the scale. The means of the Z-scores as well as their standard errors were reported in Table 4:

\begin{tabular}{|c|c|c|c|c|}
\hline & $\begin{array}{c}\text { Masculine } \\
\text { attractor }\end{array}$ & $\begin{array}{c}\text { Feminine } \\
\text { attractor }\end{array}$ & $\begin{array}{c}\text { Masculine } \\
\text { Epicene }\end{array}$ & $\begin{array}{c}\text { Feminine } \\
\text { Epicene }\end{array}$ \\
\hline $\begin{array}{c}\text { Ungrammatical sentence with } \\
\text { attractor }\end{array}$ & $-0.53(0.23)$ & $0.24(0.24)$ & $0.21(0.49)$ & $-0.73(0.29)$ \\
\hline $\begin{array}{c}\text { Ungrammatical sentence without } \\
\text { attractor }\end{array}$ & $-0.70(0.23)$ & $-0.38(0.21)$ & $-0.39(0.36)$ & $-0.08(0.73)$ \\
\hline $\begin{array}{c}\text { Grammatical sentence with } \\
\text { attractor }\end{array}$ & $0.81(0.27)$ & $-0.16(0.21)$ & $0.72(0.43)$ & $1.26(0.70)$ \\
\hline $\begin{array}{c}\text { Grammatical sentence without } \\
\text { attractor }\end{array}$ & $0.59(0.28)$ & $1.14(0.23)$ & $1.46(0.57)$ & $-0.08(0.34)$ \\
\hline
\end{tabular}

Table 4: Z-scores means and standard error of the acceptability judgment experiment

A linear mixed-effect model was created with the same fixed and random effects of the eyetracking experiment. And by using the anova function, we found a significant main effect of grammaticality of the sentence in our model: $\mathrm{F}(1,1.88)=46.8, \mathrm{p}<0.0001$; a quite strong trend towards significance for the factor type of attractor: $\mathrm{F}(4,1.88)=40.8 \mathrm{p}=0.058$; and a significant interaction between the factors grammaticality of the sentence, presence of attractor and type of attractor: $\mathrm{F}(4,1.88)=2.8, \mathrm{p}<0.037$.

The grammaticality factor was relevant, for example, when comparing the presence of masculine attractors in grammatical and in ungrammatical sentences, that is, grammatical sentences with masculine (T-test, $\mathrm{p}<0.001)$ and feminine epicene $(\mathrm{p}=0.007)$ attractors were rated more positively than ungrammatical sentences, as already expected.

The type of attractor influence was found, for example, when comparing the presence of masculine and feminine attractors in ungrammatical sentences and in grammatical sentences. This way, feminine attractors in ungrammatical sentences caused positive rates unlike masculine attractors (T-test, $\mathrm{p}=0.01)$ and feminine epicene attractors $(\mathrm{p}=0.007)$ On the other hand, in grammatical sentences, the feminine attractors received negative rates unlike, for example, the masculine attractors (T-test, $\mathrm{p}=0.04)$ and feminine epicenes $(\mathrm{p}=0.07)$.

The presence of attractor was also decisive when comparing ungrammatical and grammatical sentences with and without feminine attractors: ungrammatical sentences with feminine attractors were rated positively differently from those sentences without (T-test, $\mathrm{p}=0.02$ ), whereas grammatical sentences with attractors were rated negatively unlike those sentences without ( $\mathrm{T}$-test, $\mathrm{p}=0.002$ ). It should be noted that grammatical sentences without feminine epicenes were rated negatively unlike those sentences with $(\mathrm{p}=0.04)$.

4.5 DisCUSSION. Our results indicate that feminine attractors are responsible for grammaticality and ungrammaticality illusions, that is, ungrammatical sentences were treated as if grammatical and grammatical sentences were treated as if ungrammatical in the presence of feminine attractors. These illusions may be caused by the salience and markedness of the feminine features. Therefore, feminine attractors seem to "save" ungrammatical sentences probably because they might have been retrieved as the semantic antecedents as the off-line results of the 
eye-tracking suggest. On the other hand, for this same reason, the feminine attractors "confuse" the parser in such a way that grammatical sentences were treated as if ungrammatical, causing a break down effect when the sentence is processed.

Curiously grammatical sentences was positively overrated with the presence of a feminine epicene, which might be evidence that due to its feminine, and more importantly, due to its grammatical gender, they might be have been also considered pronominal antecedents in grammatical sentences, similarly to the feminine attractors, "helping" the parser when they are present in the sentence, but "confusing" it when they do not match the pronoun. In the latter case, despite the fact they mismatch the pronoun cues, the readers may be so inclined to retrieve them as antecedents that the parser turns out to suffer a break down, judging these sentences as ungrammatical.

5. General Discussion. This research investigated how Principle B structural constraints and gender agreement features influence coreference processing in Brazilian Portuguese, which is a language with rich morphology. In addition, we compared how different types of gender features (masculine versus feminine, grammatical gender versus semantic gender) resulted in on-line and off-line differences in our experiments. We first hypothesized that because Brazilian Portuguese is a language with morphology richness, gender features would play a major role throughout coreference processing. The results of both experiments, the eye-tracking and the grammaticality judgment, indicate that our first hypothesis was partially proved. We did not find a pervasive influence of gender features in the results; however, it seems that they play an essential role in the beginning and after coreference processing, whereas Principle B structural constraints appear to play a major role at late processing phases as well as after coreference processing. This way, our results provide evidence in favor of the constraint-based account (Badecker \& Straub, 2002), which argues that initially only discourse salience and agreement features influence the antecedent candidate set, and that the structural constraints would only operate at late processing phases. It should be noted that the present research could also contribute to the literature with off-line measures. Our off-line results of both the eye-tracking and the grammaticality judgment experiments show that both agreement features and Principle B constraints influence comprehension and acceptability judgments in an after-processing phase.

The results of our both experiments also suggest that antecedent retrieval works in a ContentAddressable fashion (McElree, 2000; McElree et al, 2003; van Dyke and McElree, 2006) since content cues such as agreement features as well as structural constraints are both taken into account in ungrammatical and grammatical contexts. First, in ungrammatical sentences, when the structurally acceptable antecedent does not feature-match the pronoun, the presence of feminine attractors, in general, appear not only to facilitate coreference processing at early processing phases, but also to make these sentences be treated as grammatical in off-line measures, which can be considered an illusion of grammaticality. In addition, the use of agreement cues by the parser can also affect comprehension since feminine attractors caused more trouble for the readers to retrieve the structurally acceptable antecedent, which may be evidence that they may be retrieved as the semantic antecedent in these cases, creating semantic illusions as well. Second, in grammatical sentences, the presence of feminine attractors cause slower coreference processing in the beginning of processing as a result of the interference effects (Lewis \& Vasishth, 2005; Lewis, Vasishth \& van Dyke, 2006) caused by the similarity between the structurally unacceptable antecedent and the pronoun cues. This accompanied by the fact that these sentences were considered ungrammatical by the comprehenders may indicate an illusion 
of ungrammaticality. Differently, from ungrammatical sentences, the presence of feminine attractors do not seem to create semantic illusions, on the contrary, it seems to facilitate the semantic retrieval of the structurally acceptable antecedent as if it were a priming effect.

Our second hypothesis was proved true, that is, memory accessing is not that abstract and different types of features are responsible for differences in memory retrieval. The results of both experiments showed that the feminine gender in general is very influential in memory retrieval when compared to the masculine gender. Additionally, because the gender information of the epicene attractors can be quickly accessed by the parser, they display greater influence in memory retrieval than the attractors that have semantic gender. This way, their facilitation effects and similarity effects are stronger in ungrammatical and in grammatical sentences respectively.

6. Conclusion To sum up, content addressable memory (CAM) seems to be adequate to explain the influences of the agreement cues and structural constraints cues in how antecedents are retrieved from memory in Brazilian Portuguese. It seems that not all cues are accessed or used at the same time since our results show that at early processing phases, coreference processing seems to be influenced by agreement features; at late processing phases, it may be influenced by structural constraints; and after processing, coreference comprehension and acceptability judgment appear to be influenced by both agreement features and structural constraints. Additionally, the agreement cues are not taken into account by the parser at the same way either. Feminine features and grammatical gender features must be stored differently from other types of gender in our memory as they show different patterns in memory retrieval. Finally, the influences of attractors are so robust in Brazilian Portuguese that they can be responsible for grammatical, ungrammatical and semantic illusions.

\section{References}

Arnold, J., Eisenband, J., Brown-Schmidt, S.,Trueswell, J. 2000. The rapid use of gender information: evidenceof the time course of pronoun resolution from eyetracking. Cognition 76.

Cacciari, C., Carreiras, M. \& Cionini, C. 1997. When words have two genders: anaphor resolution for Italian functionally ambiguous words. In: Journal Memory and Language, volume 37, issue 4, pages 517-532.

Cacciari, C., Corradini, P., Padovani, R., Carreiras, M. 2011. Pronoun resolution in Italian: the role of grammatical gender and context. In: Journal of Cognitive Psychology. London, UK: Psychology Press. http://dx.doi.org/10.1080/20445911.2011.526599.

Chomsky, N. 1981. Lectures on Government and Binding. Dordrecht: Foris.

Chomsky, N. 1995. The Minimalist Program, Current Studies in linguistics 28, MIT Press, Cambridge, MA,.

Chow, W.; Shevaun, L. and Phillips, C. 2014. Immediate sensitivity to structural constraints in pronoun resolution. Frontiers in Psychology. 5, article 630.

Clifton, C., Frazier, L., \& Deevy, P. 1999. Feature manipulation in sentence comprehension. Rivista di Linguistica, 11, 11-39.

Cunnings, I., Felser, C. 2013. The role of working memory in the processing of reflexives. Lang.Cogn.Process. 28,188-219. http://dx.doi.org/10.1080/01690965.2010.548391. 
Di Domenico, E. \& De Vicenzi, M.. 1995. Gender and number in the retrieval of pronoun antecedents in use and representation. In: Nash, L., Tsoules, F., Zribi-Herts, A. (Eds.), Actes Du deuxième colloque 'Languages ET grammaire'. Paris, 95-109.

Dillon, B., Mishler, A.,Sloggett, S., Phillips, C. 2013. Contrasting intrusion profiles for agreement and anaphora: Experimental and modeling evidence. Journal of Memory and Language 69 85-103.http://dx.doi.org/10.1016/j.jml.2013.04.003.

Grosz, B., Joshi, A. and Weinstein, S. 1995. Centering: A Framework for Modeling the Local Coherence of Discourse. Computational Linguistics v. 21, n. 2.

Kennison, S. M. 2003. Comprehending the pronouns her, him, and his: Implications for theories of referential processing. Journal of Memory and Language. 49, 335-352.

Lewis, R. L. \& Vasishth, S. 2005. An Activation-Based Model of Sentence Processing as Skilled Memory Retrieval. Cognitive Science 29, 375-419.

Lewis, R.L., Vasishth, S., and Van Dyke, J.A. 2006. Computational principles of working memory in sentence comprehension. Trends Cogn. Sci.(Regul.Ed)10, 44-54.

McElree, B. 2000. Sentence comprehension is mediated by content addressable memory structures. Journal of Psycholinguistic Research, 29, 111-123.

McElree, B., Foraker, S., \& Dyer, L. 2003. Memory structures that subserve sentence comprehension. Journal of Memory and Language, 48, 67-91.

Nicol, J. and Swinney, D.A. 1989. The role of structure in coreference assignment during sentence comprehension. J. Psycholinguist. Res. 18, 5-19.

Patil, U., Vasishth, S., Lewis, R. 2016. Retrieval interference in syntactic processing: The case of reflexive binding in English. Frontiers of Psychology 7:329. http://dx.doi.org/10.3389/fpsyg.2016.00329.

Phillips, C; Wagers, M; Lau, E. 2011. Grammatical illusions and selective fallibility in real-time language comprehension. In: Experiments at the Interfaces. Syntax and Semantics. 37, 147-180.

Rigalleau, F., Caplan D. and Baudiffier, V. 2004. New arguments in favor of an automatic gender pronominal process, The Quarterly Journal of Experimental Psychology Section A: Human Experimental Psychology, 57:5, 893-933.

Sturt, P. 2003 The time-course of the application of binding constraints in reference resolution. Journal of Memory and Language 48, 542-562.

Van Dyke, J., McElree, B, 2006. Retrieval interference in sentence comprehension. Journal of Memory and Language 55,157-166. http://dx.doi.org/10.1016/j.jml.2006.03.007.

Van Dyke, J., McElree, B, 2011. Cue-dependent interference in comprehension. Journal of Memory and Language 65, 247-263. http://dx.doi.org/10.1016/j.jml.2011.05.002.

Xiang, M., Dillon, B. and Phillips, C. 2009. Illusory licensing effects across dependency types: ERP evidence. Brain \& Language 108, 40-55. 